\title{
LA INCONSTITUCIONALIDAD EN RAZÓN DE FORMA DE LA LEY N 19.889 APROBADA POR EL PROCEDIMIENTO DE DECLARATORIA DE URGENTE CONSIDERACIÓN.
}

\author{
THE UNCONSTITUTIONALITY BY REASON OF FORM OF LAW N ${ }^{\circ} 19,889$ \\ APPROVED BY THE URGENT CONSIDERATION DECLARATION PROCEDURE
}

\section{A INCONSTITUCIONALIDADE POR MOTIVO DA FORMA DA LEI N ${ }^{\circ} 19.889$ APROVADA PELO PROCEDIMENTO DE DECLARAÇÃO DE CONSIDERAÇÃO URGENTE}

\author{
Pablo Rodríguez Almada* \\ "Es muy veleidosa la probidad de los hombres, \\ sólo el freno de la Constitución puede afirmarla" \\ José Artigas \\ (Discurso inaugural \\ al Congreso de abril de 1813)
}

RESUMEN. El día 23 de abril de 2020, el Poder Ejecutivo envió al Poder Legislativo, un proyecto de ley con declaratoria de urgente consideración que contenía 501 artículos e infinidad de temas. Este proyecto de ley fue sancionado el día 6 de julio de 2020 con 476 artículos, promulgado el día 9 de julio de 2020, publicado en el Diario Oficial el día 14 de julio de 2020 y entró en vigencia el día 24 de julio de 2020 con el $N^{\circ} 19.889$. Este artículo tiene la finalidad de investigar respecto de si el Poder Ejecutivo, cuando presentó el proyecto de ley con declaratoria de urgente consideración al Poder Legislativo, con el volumen de artículos y materias que contiene, cometió desviación de poder y atentó contra el principio de separación o división de poderes. Además se analizará, si la interpretación del vocablo "urgencia" y las materias incluidas en el texto de la ley que son inconexas entre sí, produjo una mutación de la Constitución. Por último, se analizará si al activar el mecanismo de elaboración de la ley con el rótulo de urgente consideración, se podría interpretar que los inscriptos habilitados para votar, no tienen la potestad de interponer el recurso de referéndum. En definitiva se concluirá, que al haber entrado en vigencia la ley $\mathrm{N}^{\circ} 19.889$, con el procedimiento de declaratoria de urgente consideración, con todas las anomalías referidas, es una ley inconstitucional en razón de forma.

\footnotetext{
* Doctor en Derecho y Ciencias Sociales de la Universidad de la República, Uruguay. Docente de "Principios Generales de Derecho" en la Facultad de Ciencias Empresariales de la Universidad Católica del Uruguay. Postgrado de Especialización en Derecho Constitucional y Derechos Humanos, Universidad Católica del Uruguay. Editor Científico de la Revista de Derecho (UCUDAL). Correos electrónicos: rodriguezalmadapablo@gmail.com pablo.rodriguez@ucu.edu.uy
} 
PALABRAS CLAVE. Proyecto de ley con declaratoria de urgente consideración. Desviación de poder. Mutación Constitucional. Principio de Separación de Poderes. Referéndum. Inconstitucionalidad.

ABSTRACT. On April 23, 2020, a bill declared of urgent consideration was sent by the Executive Power to the Parliament which consisted of 501 articles and countless subject matters. This bill was passed on July 6, 2020 with 476 articles; it was enacted on July 9, 2020; published in the Official Gazette on July 14, 2020; entered into force on July 24, 2020, and became Law 19,889. This paper intends to investigate if the Executive Power committed a deviation of power and attempted against the Principle of Separation of Powers upon proposing this bill declared of urgent consideration to the Legislative Power containing such amount of articles and subject matters. In addition, there shall be an analysis on whether the interpretation of the word "urgency" and the subject matters included in the language of the law, which are unconnected to each other, produced a so called unconstitutional mutation. Finally, it shall be analyzed if activating the mechanism of the bill with the "urgent consideration" label, could be interpreted as if registered voters are not entitled to file a referendum. Ultimately, it shall be concluded that Law 19,889, having entered into force through the procedure of the declaration of urgent consideration with all the aforementioned anomalies, is an unconstitutional law in terms of form.

KEY WORDS. Bill declared of urgent consideration; Power deviation; Constitutional mutation; Principle of Separation of Powers; Referendum; Unconstitutionality.

ABSTRACT. Em 23 de abril de 2020, o Poder Executivo encaminhou ao Legislativo um projeto de lei com declaração de urgência que continha 501 artigos e inúmeros temas. Este projeto foi sancionado em 6 de julho de 2020 com 476 artigos, promulgado em 9 de julho de 2020, publicado no Diário Oficial em 14 de julho de 2020 e entrou em vigor em 24 de julho de 2020 com o No. 19.889. Este artigo tem por objetivo investigar se o Poder Executivo, ao apresentar o projeto de lei com declaração de urgência ao Poder Legislativo, com o volume de artigos e matérias que contém, cometeu um desvio de poder e atentou contra o princípio de separação ou divisão de poderes. Além disso, será analisado se a interpretação da palavra "urgência" e as matérias do texto da lei que se desviam entre si, produziram uma mutação constitucional. Por fim, será analisado se ao ativar o mecanismo de redação da lei com a etiqueta de consideração urgente, poderia ser interpretado que as pessoas inscritas habilitadas a votar não têm competência para interpor recurso de referendo. Em última análise, é concluído que, tendo entrado em vigor a Lei ${ }^{\circ} 19.889$, com o procedimento de declaração de urgência, com todas as anomalias referidas, é uma lei inconstitucional em termos de forma. 
PALAVRAS CHAVE. Projeto de lei com declaração de consideração urgente. Desvio de poder. Mutação constitucional. Princípio de separação de poderes. Referendo. Inconstitucionalidade.

\section{INTRODUCCIÓN}

I.1) La Constitución del año 1967 incorporó el instituto de proyecto de ley con declaratoria de urgente consideración en el artículo 168 numeral $7^{\circ}$, a efectos de reforzar las facultades del Poder Ejecutivo (Korzeniak, 2008), procurando acelerar el proceso de discusión y sanción de la ley (Barbagelata, 1985).

En esta clase de proyecto ley, el Poder Ejecutivo tiene iniciativa privativa, pero para presentar un proyecto de ley con esta característica, tiene que actuar en Consejo de Ministros (artículo 160 de la Constitución), esto significa que se debe presentar con las firmas del presidente de la República conjuntamente con las de la mayoría de los ministros, previa convocatoria a todos (artículos 162 y 168 numeral 25 de la Constitución).

De la Constitución del año 1967, surgía que la presentación de un proyecto de ley con el rótulo de urgente consideración al Poder Legislativo, provocaba que la discusión en las cámaras se debía realizar en plazos acotados, esto es, 45 días en cada cámara, y si los legisladores no se pronunciaban en dichos plazos quedaba sancionado el proyecto de ley en forma ficta.

Esta tendencia de reforzar al Poder Ejecutivo en detrimento del Poder Legislativo, se acentuó en la reforma constitucional del año 1996, y como uno de los ejemplos de ello es en la aprobación de leyes en forma ficta (Moreira, 1998), porque en el proyecto de ley con declaratoria de urgente consideración, el plazo de discusión de la segunda cámara se redujo de 45 días a 30 días, acotando las posibilidades de estudio del proyecto de ley por parte de los legisladores de la segunda cámara.

I.2) Desde que existe este procedimiento para elaborar leyes, se ha utilizado en escasas oportunidades y en la mayoría de las mismas en forma adecuada.

Desde el advenimiento de la democracia, en el año 1985, hasta el año 2019, se había utilizado el mecanismo de urgente consideración, por parte del Poder Ejecutivo, en 13 oportunidades, siendo rechazados 4 proyectos de ley y aprobadas 9 leyes que se tramitaron con este rótulo.

Los proyectos de ley con declaratoria de urgente consideración más extensos que se presentaron en el período de 1985 a 2019 fueron los siguientes: uno del periodo del 
gobierno del presidente doctor Luis Alberto Lacalle Herrera (1990-1995), presentado en abril de 1992, que refería a la modificación del régimen de pasividades que contaba con 92 artículos, que no fue aprobado; otro en el gobierno del presidente doctor Jorge Batlle (2000-2005), presentado en abril de 2000, con una extensión de 89 artículos, que fue aprobado (actual ley $\mathrm{N}^{\circ} 17.243$ ); y otro también en el gobierno del doctor Jorge Batlle, presentado en noviembre de 2000, con una extensión de 91 artículos, que fue aprobado (actual ley $\mathrm{N}^{\circ}$ 17.292) (Chasquetti, 2020).

Los tres proyectos de ley mencionados, que no alcanzaban los 100 artículos, eran considerados "leyes ómnibus" - “omnibus bills"- por la cantidad de temas que contenían, y como señala el politólogo Daniel Chasquetti (2020) son piezas legislativas inconvenientes para la democracia, porque impiden un tratamiento parlamentario adecuado.

El profesor José Kozeniak (2020) señala respecto de la "ley ómnibus” "con esta curiosa denominación se conocen en nuestro país leyes que comprenden en su articulado normas que por su contenido deberían encontrarse separadas...".

Es por ello que, desde el año 1985 a 2019, el Poder Ejecutivo de los gobiernos del Partido Colorado, el Partido Nacional y el Frente Amplio, utilizaron con cautela este mecanismo y en general con un contenido que permitía a los legisladores su adecuado estudio.

Sin lugar a dudas, el Poder Ejecutivo desde 1985 a 2019, salvo las excepciones referidas a los proyectos enviados en los gobiernos de los Doctores Lacalle Herrera y Batlle ya referidos, concebía la aplicación de este instrumento para momentos de "urgencia" objetiva.

1.3) Lo referido marca una diferencia con el proyecto de ley con el rótulo de urgente consideración presentado al Poder Legislativo el día 23 de abril de 2020, que contenía 501 artículos, que entrara en vigencia con el $\mathrm{N}^{\circ}$ de ley 19.889 .

El profesor Korzeniak (2020) señala que este proyecto de ley es una "ley ómnibus" por lo referido con antelación.

En el mismo sentido, en el programa "Desayunos Informales" de canal TELEDOCE, de fecha 28 de enero de 2020, el politólogo Oscar Bottinelli (2020) señaló respecto del anteproyecto de ley con declaratoria de urgente consideración -anterior al proyecto de ley de urgente consideración enviado al Poder Legislativo el 23 de abril de 2020-, que era de 457 artículos "yo digo...una ley ómnibus, no, es una "ley ferrocarril”, esta llena de vagones, cada una de las partes de la ley es una enorme ley en sí mismo, de enorme trascendencia”. 
Es por ello que el politólogo Adolfo Garcé (2020) cuando se presentó el proyecto de ley el pasado 23 de abril manifestó "Como la esperanza es lo último que se pierde, todavía alimento la ilusión de que los legisladores acuerden desglosarla en varios proyectos”, señalando que eso contribuiría a mejorar la calidad del proceso parlamentario.

Es evidente, que no existe una "urgencia” objetiva y además el volumen de artículos y temas que contiene el proyecto de ley, no permitió a los miembros de las cámaras, un estudio profundo de los diversos temas contenidos en el mismo.

I.4) El profesor Juan Pablo Cajarville (2020) señaló, que si entrara en vigencia el proyecto de ley analizado, el Poder Ejecutivo estaría cometiendo desviación de poder, y además atentando contra el principio de separación de poderes.

A esto se debe agregar que se podría interpretar que no esta permitido activar el procedimiento de recurso de referéndum contra la ley aprobada.

Por tanto, con esta ley, el Poder Ejecutivo podría estar eliminando "de un plumazo" al Poder Legislativo y al Cuerpo Electoral, que son en definitiva los representantes del pueblo el primero y el soberano el segundo.

Esto es así, porque el proyecto de ley se podría haber sancionado en forma ficta por la imposibilidad de una discusión en profundidad de los diversos temas contenidos en el mismo, por tanto, se podría haber aprobado el proyecto de ley sin pronunciamiento del Poder Legislativo. En definitiva, se sancionó el proyecto de ley en forma expresa dentro de los plazos que establece la Constitución -dentro de 45 días en la primera cámara, 30 días en la segunda cámara y 15 días cuando volvió a la primera cámara con modificaciones de la segunda- sin un estudio profundo y serio de los temas.

Además se le podría impedir al cuerpo electoral la posibilidad de derogar la ley a través del recurso de referéndum, si la Corte Electoral interpretara que al tratarse de un proyecto de ley con iniciativa privativa del Poder Ejecutivo, no esta habilitada la posibilidad de activar el instituto de gobierno directo.

En definitiva la ley con declaratoria de urgente consideración sancionada por el Parlamento, que entró en vigencia con el $N^{\circ} 19.889$, con el volumen de temas y artículos que contiene y sin que exista una "urgencia" objetiva, es inconstitucional en razón de forma. 


\section{DESVIACIÓN DE PODER}

II.1) En la sección “Cartas al Director” del semanario Búsqueda, de fecha 27 de febrero de 2020, el profesor Juan Pablo Cajarville explicó en forma sucinta y clara que si entrara en vigencia el proyecto de ley con el rótulo de urgente consideración, el Poder Ejecutivo estaría cometiendo desviación de poder.

Corresponde mencionar, que el profesor Cajarville se refería al anterior anteproyecto de ley con declaratoria de urgente consideración, que contenía alrededor de 460 artículos, no la actual ley que se presentara el 23 de abril de 2020, que contenía 501 artículos, que fuera sancionada el día 6 de julio de 2020 con 476 artículos, promulgada el día 9 de julio de 2020 y publicada el día 14 de julio de 2020.

El diputado del Partido Cabildo Abierto Eduardo Lust, de la coalición de gobierno, en el debate parlamentario de la Cámara de Diputados de fecha 8 de junio de 2020, señaló que no estaba de acuerdo con la posición de Cajarville, y manifestó que la desviación de poder se aplica a los actos administrativos no a las leyes, opinión del legislador que no compartimos.

Señaló Cajarville (2020) que la "desviación de poder" “...se configura siempre que el fin querido por el órgano estatal actuante...” en este caso el Poder Ejecutivo “... no coincida con el fin debido para el cual se le confirió el poder que se está ejerciendo”.

En el mismo sentido, el profesor Carlos Delpiazzo (2011), señala que la “desviación de poder" se configura cuando el fin querido por el órgano estatal no coincide con el fin debido impuesto por la regla de derecho, y el profesor Sayagues Laso (1987) agrega que el fin espúreo invalida el acto en forma insanable pero debe aducirlo y probarlo el perjudicado por la desviación alegada, en este caso el que fuera lesionado por la ley en su interés directo, personal y legítimo (artículo 258 inciso $1^{\circ}$ de la Constitución).

II.2) El fin querido por el Poder Ejecutivo fue aprobar un conjunto de leyes en un lapso acotado, que de otro modo, corría el riesgo que no se aprobaran si demorara mucho el trámite de su sanción, puesto que la coalición que formó para gobernar, esta integrada por cinco partidos, e históricamente las coaliciones en el Uruguay no se han mantenido todo el periodo de gobierno.

El fin debido impuesto por la norma jurídica para el cual se le confirió la potestad a dicho Poder del Estado -artículo 168 numeral $7^{\circ}$ de la Constitución- es aprobar en un plazo acotado una ley que contenga un tema o temas conexos "urgentes". 
Además, es por lo menos discutible, que normas de Derecho Penal, en las cuales rige el principio de legalidad, se puedan aprobar a través de un proyecto de ley con declaratoria de urgente consideración.

En definitiva, por lo manifestado, existe “desviación de poder" por parte del Poder Ejecutivo.

\section{INTERPRETACIÓN DEL VOCABLO “URGENTE”.}

III.1) En el debate parlamentario en la Cámara de Senadores, ocurrido el día 28 de abril de 2020, se suscitó la discusión respecto de que interpretación se le debía conferir al vocablo "urgencia".

El senador del Partido Nacional Jorge Gandini señaló al respecto "Esta no es una ley de temas urgentes, es una ley de urgente consideración... lo que reglamenta es el tiempo en el que el Parlamento tiene que aprobarla y le dice al Parlamento "si no la aprueba queda aprobada igual"...es de urgente de consideración por razones políticas...” y más adelante afirmó "Cambia más de 30 leyes... ¿Donde dice que una ley de urgente consideración tiene que tener un tema o dos, o tres o cuatro o cinco? Esta en la voluntad del Poder Ejecutivo de usar esa herramienta... ”, y finaliza diciendo “... lo que es urgente es subjetivo... la ley no trata de temas urgentes...para nosotros es de urgente consideración el cambio...".

El senador del Partido Socialista - Frente Amplio Daniel Olesker -legislador de la oposición-, se preguntó "el concepto de urgencia...si la urgencia es la urgente consideración o la urgencia de los temas..." y responde "la urgencia se encuentra... en la materia sobre la que se legisla, la declaratoria de urgencia no pone una urgencia de manifiesto, no puede declararla, no puede crearla, lo que hace es generar la urgente consideración de un tema que de por sí ya es urgente, la urgencia es un hecho objetivo, objetivable dicen los constitucionalistas. Los temas deben requerir urgencia para ser resueltos y adelanto... que ninguno de los puntos planteados en la ley reviste la condición de tratar un tema de urgencia objetivable...".

III.2) En el debate parlamentario en la cámara de Representantes, ocurrido el día 8 de junio de 2020, se planteo el mismo debate.

El diputado del Partido Colorado Conrado Rodríguez, perteneciente a la coalición de gobierno se refirió respecto de la urgencia señalando "...lo que es...de urgente consideración es una calificación que hace el Poder Ejecutivo y que se basa en aspectos formales y no sustanciales... el rótulo de urgente consideración es un poder discrecional 
del Poder Ejecutivo. Aquí no hay un estudio sobre la objetividad de lo que es urgente o lo que no es urgente, porque lo que es urgente para el Poder Ejecutivo puede no serlo para el Poder Legislativo...Por lo tanto, es muy claro lo que dice la Constitución, establece que el rótulo es un rótulo formal, y la declaratoria de urgente consideración la da el Poder Ejecutivo...".

Eldiputado delPartido CabildoAbierto doctorEduardo Lust-único constitucionalista de la coalición de gobierno- sorprendentemente no señaló algo a destacar sobre el tema "urgencia".

El diputado del Partido Nacional -partido de gobierno- Rodrigo Goñi, señaló sobre la interpretación del vocablo "urgencia” “...es el gobierno, así lo indica nuestra Constitución y así lo indican los sistemas democráticos republicanos de gobierno de todo el mundo...es el gobierno el que debe valorar cuando propone, no solamente un proyecto de urgente consideración sino cualquier proyecto legislativo o cualquier medida...".

El diputado del Partido Socialista - Frente Amplio Gonzalo Civila -legislador de la oposición- señaló sobre la "urgencia” "me preguntaba si se trata de una urgencia real o de una urgencia formal..." y refiriéndose a los temas del proyecto de ley dice "...no se trata de temas urgentes para la enorme mayoría de la sociedad uruguaya ...pero contiene temas urgentes para este gobierno..." y sobre el alcance del término "urgencia" y sobre el procedimiento de urgente consideración dijo que es "un mecanismo que esta previsto para... legislar sobre urgencias realmente existentes...".

En estas intervenciones, surgen las dos posiciones políticas respecto al concepto de "urgencia” una de la coalición de gobierno y otra de la oposición.

III.3) Ahora vamos a las opiniones autorizadas, la de los profesores de Derecho Público.

El profesor Aníbal Barbagelata (1985) no analiza en profundidad este punto y únicamente señala que la incorporación a la Constitución de este procedimiento de elaboración de las leyes responde al deseo de procurar agilizar el tratamiento de un proyecto de ley cuando el Poder Ejecutivo lo juzgue necesario. No explicita respecto del alcance o interpretación que se le debe dar a los vocablos "urgente" y "urgencia" que lucen en el artículo 168 numeral $7^{\circ}$ de la Constitución. 
El Doctor Gonzalo Aguirre Ramírez (1985) omite analizar este punto señalando que la incorporación a la Constitución de este procedimiento de elaboración de las leyes es a efectos de superar la lentitud parlamentaria, en los casos que el Poder Ejecutivo "tenga especial interés” en que el trámite de la iniciativa sea rápido. Nos preguntamos si el "especial interés" al que se refiere Aguirre Ramírez es por la "urgencia” de la situación que se quiere regular con el proyecto de ley, o por un simple interés del Poder Ejecutivo que se apruebe una ley en un plazo breve.

El profesor Cassinelli Muñoz (2009), señala que este mecanismo de elaboración de leyes es a los efectos que en plazos más o menos razonables el Poder Legislativo se pronuncie a favor o en contra respecto de una ley que el Poder Ejecutivo considere necesaria para la ejecución de su política.

No tenemos el honor de compartir la posición del maestro Cassinelli Muñoz.

Señala el profesor Cagnoni (2006) “...la regla de la razonabilidad deberá juzgar sobre la urgencia, concepto jurídico indeterminado, y no potestad discrecional”.

El profesor José Korzeniak (2020) señaló recientemente sobre el proyecto de ley de urgente consideración de 501 artículos presentado por el Poder Ejecutivo el día 23 de abril de 2020 -actual ley $\mathrm{N}^{\circ}$ 19.889- "no sólo es formalmente inconstitucional, sino un verdadero exabrupto jurídico" y fundamenta sus dichos señalando que la declaratoria de urgente consideración "no es un acto discrecional del Poder Ejecutivo, que no puede “inventar" la urgencia, sino tan sólo declararla” y más adelante refiriéndose al concepto de "urgencia" contenido en el artículo 168 numeral $7^{\circ}$ de la Constitución dice " $A$ mi juicio esta "declaratoria" consiste en poner de manifiesto una urgencia razonablemente existente, urgencia que no puede ser inventada o "constituida" por el Poder Ejecutivo". En términos técnicos indicó que, "es una decisión reglada y no discrecional y, menos aún, arbitraria, según la Constitución”.

En el mismo sentido, el profesor José Korzeniak, señalaba en el libro Primer Curso de Derecho Público -Derecho Constitucional (cuarta edición del año 2008), respecto del instituto de proyecto de ley con declaratoria de urgente consideración "En cuanto a su contenido, consideramos que los temas regulados deben tener cierta razonable urgencia en ser resueltos" y más adelante señala "El Poder Ejecutivo no debe "inventar" o "constituir" la urgencia del asunto...".

Si bien se lo puede acusar al profesor Korzeniak de tener una visión sesgada de este tema por haber sido senador del Partido Socialista - Frente Amplio, ya afirmaba 
su opinión, en el libro clásico de Derecho Constitucional de su autoría que todos los estudiantes de nuestra generación estudiamos, y en un momento que no estaba planteada la ley que estamos analizando.

El profesor Fleitas de León (2019), señala que el vocablo “declaratoria” de urgente consideración refiere a que la manifestación de voluntad del Poder Ejecutivo "debe ser declarativa -y no constitutiva- de una situación de urgencia realmente existente, que es el presupuesto de hecho y el motivo validante de la manifestación del Poder Ejecutivo en estos casos".

III.4) El profesor Carlos Delpiazzo (2011) analizando el aspecto objetivo de las irregularidades de los actos administrativos realiza algunas reflexiones que son trasladables al tema del proyecto de ley con declaratoria de urgente consideración.

Señala el jurista respecto de los motivos del acto administrativo -léase del proyecto de ley de urgente consideración- que si los hechos operantes como supuestos del acto no son como la administración -léase Poder Ejecutivo- pretende, el acto estará viciado por inexistencia de motivos.

En el mismo sentido opinaba el profesor Sayagues Laso (1987) que señalaba que la inexistencia de los motivos que justifican el acto -en este caso la "urgencia"- produce la invalidez absoluta e insanable del acto.

El profesor Felipe Rotondo (2009) señala que si no hay motivos para el acto este es ilegítimo, y esto significa que contradice una regla de derecho, en el caso de estudio la Constitución.

III.5) El Poder Ejecutivo y los legisladores de la coalición de gobierno, evidentemente sostienen la posición del senador Jorge Gandini y de los diputados Conrado Rodríguez y Rodrigo Goñi, que la determinación de la "urgencia” es potestad subjetiva del Poder Ejecutivo y no la determinación objetiva que surja de la realidad de las circunstancias que ocurren en la sociedad.

Nosotros compartimos la posición de los profesores Cagnoni, Korzeniak y Fleitas de León.

Los vocablos "urgente" y "urgencia" que surgen del artículo 168 numeral $7^{\circ}$ de la Constitución no se refieren al procedimiento para aprobar una ley sino a una situación que se debe regular en forma inmediata. La situación que se pretende regular debe ser de una "urgencia" objetiva, debe regular una situación de gravedad. No puede existir discrecionalidad y menos arbitrariedad en la determinación de la "urgencia". 
En definitiva, el proyecto de ley con declaratoria de urgente consideración, enviado por el Poder Ejecutivo al Parlamento el día 23 de abril de 2020, actual ley $\mathrm{N}^{\circ} 19.889$, es ilegítima, en este caso contraria a la Constitución, por carecer de motivo, esto es la “urgencia" objetiva, que justifica activar este procedimiento de elaboración de la ley.

\section{VULNERACIÓN DEL ARTÍCULO 168 NUMERAL $7^{\circ}$ LITERAL A) DE LA CONSTITUCIÓN.}

IV.1) El artículo 168 numeral $7^{\circ}$ literal a) de la Constitución, establece como uno de los límites que tiene Poder Ejecutivo para la presentación al Poder Legislativo de los proyectos de ley con declaratoria de urgente consideración que "...no podrá enviar a la Asamblea General más de un proyecto de ley con declaratoria de urgente consideración simultáneamente...".

La ratio legis de la norma jurídica transcrita, es que el Poder Legislativo por lo acotado del plazo que tiene para discutir el proyecto de ley de "urgencia" -en el momento que se plebiscitó la reforma constitucional, en el año 1966, el texto de la Constitución señalaba que cada cámara tenía 45 días para decidir-, lo pueda hacer en forma profunda y seria.

Para que se pueda discutir razonablemente el proyecto con el rótulo de urgente consideración, debe tratarse de un proyecto de ley que se refiera a un tema y si fuese más de uno, que se trate de temas conexos entre sí.

En el mismo sentido, el profesor Cagnoni (2006) señala "un proyecto de ley declarado de urgente consideración, sólo puede pretender regular materia específica o materias de conexión evidente entre sí, de lo contrario acumular materias de inconexa relación, será violar el principio de que no pueden enviarse más de un proyecto cada vez”.IV.2) Por tanto, si se envía un proyecto de ley de urgente consideración con temas diversos que no tienen relación uno con los otros y con 501 artículos - “ley ómnibus” o como lo denomina el politólogo Bottinelli (2020) "ley ferrocarril”-, que como ya señalamos, podrían ser no menos de 20 proyectos de ley, se vulnera el límite constitucional que le impone al Poder Ejecutivo de no presentar más de un proyecto de ley con declaratoria de urgente consideración simultáneamente.

Se esta vulnerando dicho límite porque el proyecto presentado por el Poder Ejecutivo contiene muchos temas que no son conexos entre sí. 
Dos ejemplos son las normas de seguridad pública y las normas de educación, contenidas en la ley $\mathrm{N}^{\circ} 19.889$, que deberían estar plasmadas, al menos, en dos proyectos de ley, para posibilitar un profundo debate parlamentario, puesto que por su importancia y complejidad, no se pueden tratar en plazos acotados ni se pueden aprobar en forma ficta.

IV.3) Los temas que abarca el proyecto de ley aprobado con el $\mathrm{N}^{\circ}$ de ley 19.889 son los siguientes: de seguridad pública que modifica normas del Código Penal, del Código de la Niñez y la Adolescencia, del nuevo Código del Proceso Penal (Ley $\mathrm{N}^{\circ}$ 19.293, de 19 de diciembre de 2014), de la ley de estupefacientes (Ley $\mathrm{N}^{\circ}$ 14.294, de 31 de octubre de 1974, en la redacción dada por la Ley $\mathrm{N}^{\circ} 19.513$, de 14 de julio de 2017), de la ley de procedimiento policial y de la ley orgánica policial; sobre protección de la soberanía en el espacio aéreo; sobre régimen de adopciones; sobre educación, la mayoría modificativas de la Ley de Educación $N^{\circ} 18.437$ (artículos 127 a 206 de la ley $\mathrm{N}^{\circ}$ 19.889); sobre "la regla fiscal"; respecto de formas de pago de haberes a trabajadores; de promoción a micro y pequeñas empresas; que involucran a entes autónomos y servicios descentralizados del dominio comercial e industrial del Estado; sobre desmonopolización de ANCAP; sobre modificación del régimen jurídico de la unidad reguladora de servicios de energía y agua (URSEA); sobre modificación del régimen jurídico de la Unidad Reguladora de Servicios de Comunicaciones (URSEC); sobre sociedades anónimas pertenecientes a entes autónomos y servicios descentralizados del dominio industrial y comercial del Estado; sobre transparencia en la información de los entes autónomos y servicios descentralizados del dominio industrial y comercial del Estado; sobre creación del Ministerio de Ambiente; sobre creación de la Agencia de Monitoreo y Evaluación de Políticas Públicas; sobre contratación administrativa; respecto de la creación de la Agencia Reguladora de Compras Estatales; sobre funcionarios públicos; sobre eficacia administrativa del sector portuario, sobre participación Público Privado y concesiones; sobre el Instituto Nacional de Colonización; sobre el Instituto Nacional de Carnes, sobre titularidad de inmuebles rurales y explotaciones agropecuarias; que modifican el Código Rural; a través de las cuales se crea el Instituto Nacional de la Granja, a través de las cuales se crea el Instituto Nacional de Bienestar Animal; sobre libertad de trabajo y derecho de dirección de la empresa; sobre seguridad social; sobre desarrollo de políticas sociales; sobre salud pública; respecto de emergencia en la vivienda; sobre arrendamiento sin garantía; que modifican el Código Civil; sobre protección de la libre circulación; respecto de derechos de usuarios de telefonía móvil y finalmente normas sobre áreas naturales protegidas. 
Las normas jurídicas sobre áreas naturales protegidas, contenidas en los artículos 500 y 501 del proyecto de ley con el rótulo de urgente consideración enviado por el Poder Ejecutivo al Parlamento el día 23 de abril de 2020, fue suprimida del texto final de la ley $\mathrm{N}^{\circ} 19.889$.

Por tanto, al haberse sancionado el proyecto de ley con declaratoria de urgente consideración, por los motivos explicitados, es inconstitucional en razón de forma por vulnerar el artículo 168 numeral 7 literal a de la Constitución.

\section{MUTACIÓN CONSTITUCIONAL}

V.1) La posición del Poder Ejecutivo y de los legisladores de la coalición de gobierno respecto del concepto de "urgencia", y el volumen y contenido del proyecto de ley con declaratoria de urgente consideración aprobado con el № 19.889, configuró una mutación constitucional por la interpretación errónea de la connotación del vocablo "urgente” y "urgencia" del artículo 168 numeral $7^{\circ}$ de la Constitución, y por la cantidad e inconexión de los temas que contiene dicho proyecto de ley.

El jurista y filósofo alemán Karl Loewenstein (1986) señalaba que “...la mutación constitucional... produce una transformación en la realidad de la configuración del poder político... sin que quede actualizada dicha transformación en el documento constitucional: el texto de la constitución permanece intacto”.

Los elementos de la definición de Loewenstein de "mutación constitucional" que se configuran en el caso en estudio son los siguientes: (a) cambios en el poder político por avasallamiento del Poder Legislativo y el posible avasallamiento del cuerpo electoral; (b) no se plasma en la Constitución.

El profesor Adriano Sant'Ana Pedra (2012) distingue dos clases de mutaciones constitucionales.

La primera que es una mutación constitucional legítima en la medida que se mantiene en los marcos normativos establecidos por la Constitución.

La segunda clase de mutación constitucional, Sant'Ana Pedra (2012) la denominada "inconstitucional", que se configura cuando la alteración informal de la Constitución es contraria a la misma, señalando que no puede existir una mutación constitucional derogatoria de la Constitución. 
En la doctrina uruguaya, el profesor Martín Risso Ferrand $(2017,1)$ señala que la mutación que denomina en "sentido estricto" es aquella que implica una contradicción con la Constitución.

En el mismo sentido, el profesor Diego Gamarra (2014) al referirse a las mutaciones como modificaciones de normas constitucionales por mecanismos ajenos a los procedimientos preestablecidos de reforma, denomina "mutaciones en un sentido fuerte”, aquellas que se producen en contravención de lo establecido en disposiciones contenidas en actos formales reconocidos como válidos.

V.2) Una mutación constitucional requiere necesariamente de la aceptación del cambio interpretativo propuesto como plenamente constitucional (Rollnert Liern, 2014).

El profesor Göran Rollnert Liern (2014) señala, que "En los casos polémicos el juicio definitivo sobre la legitimidad constitucional de la mutación corresponderá a la jurisdicción constitucional".

El jurista Ronald Dworkin (2008) señala refiriéndose a la potestad de los jueces de interpretar la Constitución en Estados Unidos desde la sentencia del Juez John Marshall del año 1803, que este país es una sociedad más justa de lo que habría sido si se hubieran dejado los derechos constitucionales a la conciencia de las instituciones mayoritarias, como lo son en Uruguay en la actualidad el Poder Ejecutivo y la mayoría parlamentaria que forma la coalición de gobierno.

V.3) En definitiva, en el caso que estamos analizando, la mutación constitucional opera, por la interpretación errónea que realiza el Poder Ejecutivo y los legisladores de la coalición de gobierno, del concepto de "urgente" y "urgencia", contenida en el artículo 168 numeral $7^{\circ}$ de la Constitución.

El Poder Ejecutivo y los legisladores de la coalición de gobierno, consideran que la "urgencia" es subjetiva, y por tanto, que el Poder Ejecutivo tiene discrecionalidad para presentar un proyecto de ley de urgencia.

Dicha interpretación es contraria a la Constitución, por tanto mutativa de esta, o como denomina Risso Ferrand $(2017,1)$ en su clasificación "mutación en sentido estricto".

Además, el Poder Ejecutivo interpreta erróneamente, que un proyecto de ley con declaratoria de urgente consideración, puede contener un volumen de artículos y temas ilimitados, sin conexión entre sí. 
Por tanto, en esta interpretación también existe una mutación en sentido estricto (Risso Ferrand, 2017, 1), denominada también inconstitucional (Sant'Ana Pedra, 2012).

\section{VULNERACIÓN DEL PRINCIPIO DE SEPARACIÓN DE PODERES}

VI.1) El principio de separación o división de poderes no está consagrado expresamente en la Constitución uruguaya, al igual que en las Constituciones española e italiana (García Roca, 2000; Lucas Garín, 2009), pero lo está implícitamente por el artículo 82 incisos $1^{\circ}$ y $2^{\circ}$ de la Constitución uruguaya que establece:

“La Nación adopta para su gobierno la forma democrática republicana.

Su soberanía será ejercida directamente por el Cuerpo Electoral en los casos de elección, iniciativa y referéndum, e indirectamente por los Poderes representativos que establece esta Constitución; todo conforme a las reglas expresadas en la misma”.

También esta consagrado implícitamente por el artículo 72 del mismo cuerpo normativo que dispone:

"La enumeración de derechos, deberes y garantías hecha por la Constitución, no excluye los otros que...se derivan de la forma republicana de gobierno”.

La separación o división de poderes significa que en el Estado existen centros de autoridad que tienen autonomía uno de los otros, cada uno con sus funciones, cuyo resultado es el equilibrio de los Poderes (Cagnoni, 2008).

Señala el jurista Peter Häberle (2016) que el principio de la división de poderes es tanto texto clásico desde Montesquieu como también principio constitutivo en la triada del Poder Legislativo, Poder Ejecutivo y Poder Judicial del tipo del "Estado constitucional".

Además, el principio de separación de poderes, surge del artículo 16 de la Declaración de Derechos del Hombre y del Ciudadano de 1789 cuando afirma que "toda sociedad en la que la garantía de los derechos no está asegurada, ni determinada la separación de poderes, no tiene Constitución” (García Roca, 2000; Häberle, 2016).

Como señala la profesora Lucas Garín (2009) “El sentido histórico e ideológico del principio de la separación de poderes es...evitar la concentración de poder en manos, sobre todo, del titular del Poder Ejecutivo, a fin de lograr el respeto a los derechos y libertades de los ciudadanos que, representados democráticamente, constituyen ahora el Poder Legislativo". 
VI.2) En el derecho comparado, a esta triada se le han agregado otros centros de poder con autonomía, por ejemplo los Tribunales de Cuentas o Corte de Conti en las Constituciones española e italiana respectivamente o los Bancos Centrales europeos (García Roca, 2000), o los Tribunales Constitucionales (Lucas Garín, 2009) en Alemania, Italia, España, Portugal, y varios países latinoamericanos (Chile, Colombia, Bolivia, Perú, Ecuador y Guatemala, para mencionar algunos).

Este fenómeno de la ampliación de centros de poder, se configuró en Uruguay con el Tribunal de Cuentas, el Tribunal de lo Contencioso Administrativo y la Corte Electoral, previstos a partir de la Constitución del año 1934 (Gros Espiell, 1956; Korzeniak, 2008), lo que abandona la concepción rígida del concepto de separación o división de poderes, aunque los tres centros de poder clásicos se mantienen para cumplir con las tres funciones estatales: la función administrativa, legislativa y jurisdiccional, en forma predominante, pero no absoluta.

Un ejemplo de lo que venimos diciendo, surge de la función jurisdiccional que ejerce el Tribunal de lo Contencioso Administrativo, como organismo de control de la legitimidad de los actos administrativos que expiden los órganos estatales, por tanto, a través de la función jurisdiccional, el Tribunal de lo Contencioso Administrativo controla a todos los organismos estatales.

VI.3) A pesar de la división de poderes, en el derecho comparado, han aumentado las potestades legislativas del Poder Ejecutivo, por ejemplo con la intervención de este Poder en la sanción de las leyes con la facultad de imprimir el carácter de urgente de los proyectos (Lucas Garín, 2009).

El primer texto constitucional que incorporó a los decretos de urgencia fue la Constitución austriaca de 1920 elaborada por Hans Kelsen, que contemplaba los decretos transitorios de modificación de leyes como potestad legislativa del Poder Ejecutivo (Herrera Vásquez, 1996).

El profesor García Roca (2000) fundamenta este aumento de poderes del Poder Ejecutivo en razones derivadas del intervencionismo propio de los Estados sociales, y menciona como ejemplos las disposiciones del Poder Ejecutivo con rango de ley, en especial la legislación de urgencia.

El profesor Sayagues Laso (1987) menciona a los decretos-leyes de necesidad, que son normas que dicta el Poder Ejecutivo, con valor de ley, en casos graves y urgentes, que por lo general deben someterse de inmediato a la consideración del Parlamento y menciona como ejemplo de Constituciones que autorizan esta clase de normas la Constitución italiana de 1947. 
VI.4) En la Constitución argentina, a partir de la reforma constitucional del año 1994, esta prevista la potestad del Poder Ejecutivo para dictar normas con fuerza de ley.

En la Constitución histórica argentina, no estaba contemplada la potestad legislativa del Poder Ejecutivo.

A pesar de ello éste Poder del estado ejerció función legislativa y como ejemplo de ello es que en el Gobierno de Julio Argentino Roca, en el año 1885, se ratificó por decreto el curso legal de las emisiones de moneda del Banco Nacional, y en el Gobierno de Carlos Pellegrini, en el año 1891, se dispuso la suspensión del pago de depósitos del Banco Nacional y del Banco de la Provincia de Buenos Aires, para subsanar la crisis monetaria existente. Esto fue posible porque la jurisprudencia argentina legitimó esta actitud del Poder Ejecutivo (Onaindia, 2012).

El profesor Eduardo Avalos (2012) señala respecto de las normas de urgencia de la Constitución argentina de 1994, las hipótesis de Decretos de Necesidad y Urgencia (artículo 99 inciso $3^{\circ}$ de la Constitución argentina) y los Reglamentos Delegados (artículo 76 de la Constitución argentina) que tienen algunas notas en común: a) ambos recaen sobre materias propias del Parlamento; b) como principio general, el Poder Ejecutivo no los puede emitir; c) los dos proceden ante situaciones de excepción: los de necesidad y urgencia (artículo 99 inciso $3^{\circ}$ de la Constitución argentina) ante circunstancias excepcionales que han sido calificadas por la Corte Suprema de Justicia de la Nación como de "grave riesgo social"; los Reglamentos Delegados (artículo 76 de la Constitución argentina) en situaciones de emergencia pública aunque también en "determinadas materias de administración" especificadas por algunas leyes; d) existe un control parlamentario de ambos perfilado en la Constitución argentina y desactivado luego por la ley 26.122; e) ambos integran en el lenguaje de la Corte Suprema de Justicia de la Nación la categoría de "decretos legislativos".

La ley $\mathrm{N}^{\circ} 26.122$ exige para su derogación dictamen coincidente de ambas cámaras y no hay plazo para que se pronuncie el Congreso (Avalos, 2012), por tanto, en el derecho positivo argentino es más difícil dejar sin efecto un Decreto de Necesidad y Urgencia (artículo 99 inciso $3^{\circ}$ de la Constitución argentina) o Reglamento Delegado (artículo 76 de la Constitución argentina) que aprobar un proyecto de ley, porque en el caso de esta última norma jurídica, se necesita de las dos cámaras para su aprobación, en cambio en aquellas se requieren las dos cámaras para dejarla sin efecto, pero mientras tanto, existe y se aplica.

Por tanto, en el derecho positivo argentino, el Poder Ejecutivo tiene potestad legislativa. 
Más adelante el profesor Avalos (2012) señala que con un promedio de 9,3 decretos de necesidad y urgencia por mes, el ex presidente Eduardo Duhalde $-1^{\circ}$ de enero de 2002 al 24 de mayo de 2003- fue quien los usó con mayor intensidad en proporción al tiempo que ejerció la titularidad del Poder Ejecutivo. Sin embargo fue Carlos Saúl Menem quien con 545 decretos de necesidad y urgencia dictó cuantitativamente la mayor cantidad de decretos de esta clase. Y agrega "Desde 1853 hasta 1983 se dictaron 25 reglamentos de necesidad y urgencia; mientras que desde 1983 hasta 2010, la cifra es sensiblemente mayor: 1085 ".

Esto demuestra el abuso que se ha hecho en el país vecino con este instrumento constitucional, desde el advenimiento de la democracia -año 1983- a la actualidad.

El uso ordinario de las facultades de excepción, principalmente los Decretos de Necesidad y Urgencia, ha modificado la distribución de las funciones que es uno de los fundamentos de la forma de gobierno en Argentina, convirtiéndose el Poder Ejecutivo en el principal legislador, afectando la democracia y la estabilidad institucional (Onaindia, 2012).

Es por ello que el profesor Ylarri (2015) reclama de la Corte Suprema de Justicia de la Nación argentina que ejerza un control de constitucionalidad más riguroso sobre los decretos de necesidad y urgencia y sobre la delegación legislativa, a fin de garantizar el principio de separación de poderes.

VI.5) En Perú, la Constitución del año 1979, denominó “medidas extraordinarias” a las que podía dictar el presidente de la República en materia económica y financiera cuando existiera un interés nacional, pero con la obligación de dar cuenta al Congreso (artículo 211 inciso $20^{\circ}$ de la Constitución de Perú de 1979) (Herrera Vásquez, 1996).

Parte de la doctrina peruana entre otros De la Puente y Lavalle, Cárdenas Quirós, Pacheco Barandiarán, Eguiguren Praeli y García Belaunde citados por Herrera Vásquez (1996), señaló que las “medidas extraordinarias” eran decretos de urgencia, y parte de la jurisprudencia peruana sostuvo que dichas medidas tenían rango de ley, entre otros la Corte Suprema de la República, no así el Tribunal de Garantías Constitucionales.

Las “medidas extraordinarias" que surgían de la Constitución del año 1979, se utilizaron exageradamente y en forma abusiva (Herrera Vásquez, 1996).

Entre 1980 y 1992 se detectaron 2.579 “medidas extraordinarias”, por tanto, se produjo una grave ruptura del esquema de equilibrio de poderes (Planas Silva, 1993). El catedrático de Derecho Constitucional Landa Arroyo (2003) señala que durante la vigencia de la Constitución del año 1979 se expidieron 2262 decretos de urgencia. 
La ley de control parlamentario $\mathrm{N}^{\circ} 25.397$, de 9 de febrero de 1992, reglamentó las "medidas extraordinarias", a efectos de regular su aplicación, con la finalidad de que no se utilizara en forma abusiva. Dicha ley le otorgó a las "medidas extraordinarias" fuerza de ley, solucionando la discusión doctrinal y jurisprudencial.

La Constitución peruana de 1993, en el artículo 118 inciso $19^{\circ}$, consagró los decretos de urgencia con fuerza de ley en materia económica y financiera cuando así lo requiriera el interés nacional y con cargo de dar cuenta al Congreso, excluyéndose en forma expresa la materia tributaria.

La parte final del artículo referido señala que el Congreso puede modificar o derogar los decretos de urgencia (Herrera Vásquez, 1996).

El Reglamento del Congreso de 26 de junio de 1995 determinó el "silencio positivo” para convalidar por parte del Congreso los decretos de urgencia, esto es, se convalidan los decretos de urgencia por el transcurso del plazo de 15 días y solo se emite dictamen si es desfavorable al decreto de urgencia.

Un dato importante es que en el período de gobierno de Fujimori, de julio de 1990 a noviembre de 2000 se expidieron 1655 decretos de urgencia y 1373 leyes (Landa Arroyo, 2003), lo que demuestra que el Poder Ejecutivo ejerció función legislativa en mayor medida que el Congreso.

Sin lugar a dudas, con el instrumento constitucional de los decretos de urgencia, el Poder Ejecutivo peruano está ejerciendo función legislativa en forma abusiva, rompiendo el equilibrio de poderes.

VI.6) A pesar del aumento de las potestades legislativas del Poder Ejecutivo, existen límites.

Los límites de los Poderes, y en este caso el Poder Ejecutivo, tienen relación con la democracia y el estado de derecho.

Como señala el jurista Luigi Ferrajoli (2016) la democracia es un conjunto de reglas constitucionales que aseguran los poderes de decisión de la mayoría de los gobernados o de sus representantes y, al mismo tiempo, los límites y los vínculos a tales poderes.

Señala Avalos (2012) que "En una sociedad moderna y dinámica, las relaciones de equilibrio entre los poderes constituyen una garantía para los ciudadanos. Aquí reside uno de los pilares del Estado de Derecho”. 
El Poder Ejecutivo debe tener una oposición parlamentaria fuerte que garantice el derecho al disenso (Mora-Donatto, 2010).

Por tanto, entre los límites de la potestad legislativa del Poder Ejecutivo, se debe considerar la discusión -el debate parlamentario- la cual asegura la participación de las minorías en el procedimiento legislativo (García Roca, 2000).

La participación de las minorías es una característica fundamental de una Estado democrático, y en el caso que estamos analizando nos referimos a la minoría en el Parlamento.

El Profesor Risso Ferrand (2010) señala que luego de perfeccionada la Constitución se transforma en un instrumento contramayoritario y en defensa de la Constitución.

En situaciones de mayorías parlamentarias, el Poder Ejecutivo y el Poder Legislativo pueden actuar coordinadamente desvirtuando los controles institucionales (Ruiz, 2013), en este caso, de las minorías de las Cámaras.

Ello atentaría contra el principio de separación de poderes.

Es importante no solo el control "por" el Parlamento al Poder Ejecutivo, sino también el control “en” el Parlamento, de las minorías a las mayorías, que generalmente se realiza en el debate parlamentario y la publicidad del mismo (Aragón, 1995; MoraDonatto, 2010).

El Profesor García Roca (2017) destaca la importancia de la participación de las minorías como sujetos del control a los parlamentarios, como condición necesaria para la existencia del control, pero señala que no es suficiente, porque su eficacia requiere de la colaboración de la mayoría, que debe colocar a la oposición y a las pequeñas minorías en una situación en la que puedan ejercer el control.

La oposición parlamentaria debe constituirse en un poder institucionalizado, con dos funciones fundamentales: representación y defensa de los intereses de los distintos sectores sociales que no están representados en el gobierno, y el control del gobierno teniendo una influencia en el mismo persuadiendo o impidiendo la adopción de decisiones por parte de este (Mora-Donatto, 2010).

Señala Rubio Llorente, citado por Mora-Donatto (2010) señala “...la gran protagonista del control parlamentario es la minoría, cuya apreciación crítica de la acción gubernamental debe ser inexcusablemente ofrecida a la sociedad para que ésta continúe siendo políticamente abierta $y$, por tanto, libre". 
VI.7) En el ordenamiento jurídico uruguayo el Poder Ejecutivo cumple función colegislativa, porque tiene iniciativa para proponer leyes y en algunos casos tiene iniciativa privativa, tiene la potestad de realizar observaciones totales o parciales u objeciones a los proyectos de ley sancionados por el Poder Legislativo y finalmente tiene potestad de promulgación del proyecto de ley sancionado por el Poder Legislativo.

En el caso en estudio - proyecto de ley con declaratoria de urgente consideraciónel Poder Ejecutivo tiene iniciativa privativa, pero como ya se expresara, el abuso de las formas, sin que haya una "urgencia objetiva" en la aprobación del proyecto de ley, y con un volumen de artículos y temas que no pudo ser estudiado en forma profunda por los legisladores, por lo acotado de los plazos para su consideración, hizo que se aprobara en forma expresa, pero, sin un estudio pormenorizado de su articulado, por tanto, esto provocó el avasallamiento del Poder Legislativo.

Pero, a pesar del avasallamiento del Poder Legislativo, en forma escueta existió control "por" el Parlamento del Poder Ejecutivo, y control "en" el Parlamento de la minoría a la mayoría del Poder Legislativo.

El proyecto de ley con declaratoria de urgente consideración enviado por el Poder Ejecutivo al Parlamento contenía 501 y se aprobó la ley N 19.889 con 476 artículos.

La disminución de artículos se debió a que los partidos de la coalición de gobierno y la oposición, no votaron algunos temas planteados por el gobierno.

Una hipótesis de control "por" el Poder Legislativo al Poder ejecutivo surge de las normas sobre áreas naturales protegidas, contenidas en los artículos 500 y 501 del proyecto de ley con el rótulo de urgente consideración enviada por el Poder Ejecutivo al Parlamento, que fuera suprimida del texto final de la ley $\mathrm{N}^{\circ} 19.889$, porque partidos que integran la coalición de gobierno, y la oposición no estaban de acuerdo con dichas normas.

Una hipótesis de control “en” el Parlamento de las minorías respecto de las mayorías ocurrió en el capítulo de la ley $\mathrm{N}^{\circ} 19.889$ denominado "Normas sobre adolescentes privados de libertad" (artículos 75 a 80 de la ley $N^{\circ}$ 19.889). En la antigua redacción del proyecto de ley enviado por el Poder Ejecutivo al Parlamento, lo referente a los adolescentes privados de libertad, se encontraba en los artículos 74 a 79, y eran normas regresivas en materia de derechos para los adolescentes en conflicto con la ley penal (Rodríguez Almada, 2020). 
La minoría en el Parlamento, si bien no estaba de acuerdo con la inclusión de dichas normas en la ley referida, en la discusión e intercambio de ideas, logró modificar mejorando su contenido.

Un ejemplo es el artículo 75 del proyecto de ley con declaratoria de urgente consideración enviada por el Poder Ejecutivo al Parlamento, que modificaba el artículo 91 del Código de la Niñez y la Adolescencia, establecía en la parte que nos interesa:

“(Duración de las medidas de privación de libertad). Sustitúyese el artículo 91 de la Ley $N^{\circ}$ 17.823, de 7 de septiembre de 2004 (Código de la Niñez y la Adolescencia), el que quedará redactado de la siguiente forma:

“Artículo 91 (Duración de las medidas de privación de libertad). La medida de privación de libertad tendrá una duración máxima de diez años. En ningún caso el adolescente que al llegar a los dieciocho años permanece sujeto a medidas, cumplirá lo que le resta en establecimientos destinados a los adultos...".

Y el artículo 76 de la ley $\mathrm{N}^{\circ} 19.889$, que modificó el artículo 75 del proyecto de ley con declaratoria de urgente consideración establece:

“(Duración de las medidas de privación de libertad).- Sustitúyese el artículo 91 del Código de la Niñez y la Adolescencia, por el siguiente:

"ARTÍCULO 91. (Duración de las medidas de privación de libertad).- La medida de privación de libertad tendrá una duración máxima de cinco años, con excepción de la comisión de los delitos de: homicidio intencional agravado y muy especialmente agravado (artículos 311 y 312 del Código Penal), violación (artículo 272 del Código Penal) y abuso sexual especialmente agravado (artículo 272 TER del Código Penal), en cuyo caso la medida de privación de libertad tendrá una duración máxima de diez años. En ningún caso el adolescente que al llegar a los dieciocho años permanezca sujeto a medidas, cumplirá lo que le resta en establecimientos destinados a los adultos....".

La minoría del Parlamento logró mitigar la tendencia regresiva de las normas referidas a los adolescentes en conflicto con la ley penal.

Esa es la virtud de la discusión en el Parlamento, que la minoría controla a la mayoría e inclusive puede lograr un cambio en la ley que envía el Poder Ejecutivo.

Este control se logró en forma mínima en la discusión de la ley $\mathrm{N}^{\circ} 19.889$, por lo acotado de los plazos para discutir el proyecto de ley. 
VI.8) Si esta práctica legislativa del Poder Ejecutivo se hiciera costumbre, y este es un antecedente grave, en los hechos se podría suprimir de facto el Poder Legislativo o por lo menos las minorías del Parlamento.

Tenemos que observar los ejemplos de Argentina y Perú, entre otros.

En los países latinoamericanos referidos, se ha ampliado la práctica del Poder Ejecutivo de aprobar Decretos de Necesidad y Urgencia (artículo 99 inciso $3^{\circ}$ de la Constitución argentina), Reglamentos Delegados (artículo 76 de la Constitución argentina), Medidas Extraordinarias (artículo 211 inciso $20^{\circ}$ de la Constitución de Perú de 1979), Decretos de Urgencia con Fuerza de Ley (artículo 118 inciso $19^{\circ}$ de la Constitución de Perú de 1993), debilitando el rol del Poder Legislativo.

VI.9) Puede ocurrir en Uruguay, como en los ordenamientos jurídicos argentino y peruano, que el Poder Ejecutivo pretenda disminuir o eliminar la injerencia del Poder Legislativo en la función legislativa.

Si bien esa tendencia vulneraría el principio de separación o división de poderes, existe la Suprema Corte de Justicia como órgano garante de la Constitución.

Es por ello que es conveniente y necesario que la ley $\mathrm{N}^{\circ} 19.889$, que entró en vigencia a través del procedimiento de proyecto de ley con declaratoria de urgente consideración, ante una solicitud de inconstitucionalidad de la misma, la Suprema Corte de Justicia acoja la acción, excepción o solicitud por la vía de oficio de inconstitucionalidad, como forma de preservar el principio de separación de poderes.

\section{RECURSO DE REFERÉNDUM CONTRA LA LEY SANCIONADA CON EL PROCEDIMIENTO DE DECLARATORIA DE URGENTE CONSIDERACIÓN}

VII.1) El recurso de referéndum fue incorporado a nuestro ordenamiento jurídico en la Constitución del año 1967 (Korzeniak, 2008).

El artículo 79 inciso $2^{\circ}$ de la Constitución consagra este instituto o mecanismo de gobierno directo (Cagnoni, 2006; Correa Freitas, 2007; Korzeniak, 2008; Gutiérrez, 2012), como instrumento de control de leyes (De Armas y Garcé, 1999), a efectos de poder derogarlas, pero impone límites al cuerpo electoral.

Uno de los límites que impone el mecanismo de referéndum a las personas habilitadas para votar, es que no se puede interponer este recurso contra leyes que requieran iniciativa privativa del Poder Ejecutivo. 
El proyecto de ley con declaratoria de urgente consideración, es de iniciativa privativa del Poder Ejecutivo, de acuerdo al artículo 168 numeral $7^{\circ}$ de la Constitución.

En definitiva, se podría interpretar que el cuerpo electoral no tiene la potestad de activar el mecanismo de recurso de referéndum para derogar la ley $\mathrm{N}^{\circ} 19.889$.

El organismo que tiene el rol de controlar la regularidad de procedimiento de referéndum es la Corte Electoral, que es, como ya señalamos, un organismo que desde la Constitución del año 1934 se ha agregado a la triada clásica de Poderes conjuntamente con el Tribunal de Cuentas y el Tribunal de lo Contencioso Administrativo.

En definitiva, la Corte Electoral podría interpretar que no corresponde el recurso de referéndum contra las leyes en las cuales se aplicó el procedimiento de proyecto de ley con declaratoria de urgente consideración.

El organismo referido podría hacer dicha interpretación porque, como ya señalamos, el Poder Ejecutivo tiene iniciativa privativa para presentar dicho proyecto de ley.

Esa interpretación literal sería contraria a lo que el Poder Constituyente aprobó cuando se plebiscitó la Constitución del año 1967 en las elecciones nacionales del año 1966.

VII.2) El Poder Constituyente, que en el caso de la Constitución del año 1967 eran los ciudadanos, no crearon en la misma Constitución el instituto de proyecto de ley con declaratoria de urgente consideración (artículo 168 numeral $7^{\circ}$ ) y el instituto de referéndum (artículo 79 inciso $2^{\circ}$ ), para que el segundo se transformara en un instituto de gobierno directo inoperante, es decir "letra muerta".

Si la Corte Electoral realizara una interpretación literal de los artículos 79 inciso 2 y 168 numeral $7^{\circ}$ de la Constitución, se transformaría en una mutación constitucional denominada por Sant'Ana Pedra (2012) inconstitucional y denominada por Risso Ferrand $(2017,1)$ mutación en sentido estricto, en este caso por la interpretación errónea que realice el organismo referido de dichas normas constitucionales.

VII.3) Cuando el artículo 79 inciso $2^{\circ}$ de la Constitución limita el recurso de referéndum contra las leyes, señalando que no se puede interponer este recurso contra leyes que para su aprobación requieran "...la iniciativa ... privativa del Poder Ejecutivo", no refiere a la hipótesis del artículo 168 numeral $7^{\circ}$ de la Constitución. 
En realidad, los límites de las personas inscriptas habilitadas para votar para interponer el recurso de referéndum contra la ley refieren a las materias en las cuales tiene iniciativa privativa del Poder Ejecutivo (Gros Espiell y Arteaga, 1991), esto es por ejemplo, autorizar la deuda pública nacional (artículo 85 numeral $6^{\circ}$ de la constitución), establecimiento o modificaciones de causales jubilatorias (artículo 86 inciso $2^{\circ}$ de la Constitución), establecer exoneraciones tributarias (artículo 133 inciso $2^{\circ}$ de la Constitución), creación de Ministerios (artículo 174 de la Constitución), disponer expropiaciones para planes y programas de desarrollo económico (artículo 231 de la Constitución), exoneración temporaria de tributos nacionales o rebaja de alícuotas a las empresas que se instalen en el interior del país (artículo 298 numeral $3^{\circ}$ de la Constitución). En el mismo sentido opina Aguirre Ramírez (2008).

La interpretación que se haga del artículo 79 inciso $2^{\circ}$ de la Constitución, no puede extender los límites para interponer el recurso de referéndum a la situación de la ley $\mathrm{N}^{\circ} 19.889$, que tiene relación a un procedimiento y no a materias que tengan iniciativa privativa el Poder Ejecutivo.

Acaso puede contener la ley $\mathrm{N}^{\circ} 19.889$ aprobada por el procedimiento de declaratoria de urgente consideración presentada el 23 de abril de 2020, temas que son iniciativa privativa del Poder Ejecutivo.

Un ejemplo de materia contenida en la ley referida, que es de iniciativa privativa del Poder Ejecutivo, es la creación de un Ministerio.

Los artículos 291 a 304 de la ley $N^{\circ} 19.889$ que estamos analizando, crearon el Ministerio de Ambiente.

Ese tema -creación de un Ministerio- que necesita iniciativa privativa del Poder Ejecutivo de acuerdo al artículo 174 de la Constitución, no es susceptible del recurso de referéndum.

Pero contra los temas dentro de la ley de urgente consideración, que no sean materia privativa del Poder Ejecutivo, se puede interponer recurso de referéndum.

De otro modo, un instituto creado en una Constitución, en este caso en la Constitución del año 1967, se anularía por otro instituto creado en la misma Constitución.

El Poder Constituyente no creó el recurso de referéndum para que se transforme en inoperante.

En definitiva, se debe concluir, que contra la ley $\mathrm{N}^{\circ} 19.889$ se puede interponer recurso de referéndum. 


\section{LA INCONSTITUCIONALIDAD DE LA LEY CON DECLARATORIA DE URGENTE CONSIDERACIÓN Nº 19.889.}

VIII.1) Como señala el profesor Manuel Aragón (1995), el control es un elemento inseparable de la Constitución, por tanto, forma parte del concepto de Constitución, y en definitiva cuando no hay control, no ocurre sólo que la Constitución vea debilitadas o anuladas sus garantías o que se haga difícil o imposible su realización, ocurre simplemente que no hay Constitución.

El control del poder, principalmente el control del poder de los Poderes políticos -Poder Ejecutivo y Poder Legislativo- es fundamental para que exista un equilibrio entre estos y no se vulnere el principio de separación o división de poderes, pilar fundamental del Estado de derecho.

Una sociedad donde no este determinada la separación de poderes carece de Constitución (Flores-Dapkevicius, 2010).

VIII.2) En Uruguay, el control del poder que ejercen los Poderes políticos -Poder Ejecutivo y Poder Legislativo- por parte del Poder Judicial, en el caso analizado, es fundamental.

El Poder Judicial, y en este caso la Suprema Corte de Justicia -por tener el ordenamiento jurídico uruguayo un sistema de control de constitucionalidad concentrado-, deberá aplicar en el control de constitucionalidad los principios de supremacía de la Constitución y de interpretación conforme a la Constitución (Risso Ferrand, 2017, 2; Vázquez, 2018).

VIII.3) En el tema en estudio, en primer término, existe desviación de poder por parte del Poder Ejecutivo, porque como ya dijimos, el fin querido por dicho Poder al presentar el proyecto de ley con el rótulo de urgente consideración, no coincide con el fin debido impuesto por la Constitución.

El fin querido por el Poder Ejecutivo, es aprobar una serie de leyes, a través de una "ley ómnibus" o "ley ferrocarril", en el primer año de gobierno, a efectos de aplicar la política de gobierno que pretende con prontitud, mientras conserve la coalición de cinco partidos políticos que ha formado.

El fin debido por la Constitución, es que el Poder Ejecutivo presente un proyecto de ley con el rótulo de urgente consideración cuando sea objetivamente "urgente". 
VIII.4) Respecto de los motivos por los cuales se presenta el proyecto de ley con declaratoria de urgente consideración no son tales.

E1 Poder Ejecutivo y los legisladores de la coalición, sostienen que la determinación de la "urgencia" es potestad subjetiva del Poder Ejecutivo y no la determinación objetiva que surja de la realidad de las circunstancias que ocurren en la sociedad en este momento.

Sostenemos la posición de los catedráticos de Derecho Constitucional Aníbal Cagnoni y José Korzeniak que han opinado que no puede existir discrecional por parte del Poder Ejecutivo respecto de la determinación de la "urgencia”, esto significa que no se puede declarar la "urgencia", sino que tiene que existir a priori.

En definitiva, existe una mutación constitucional en la interpretación del vocablo "urgencia" que realiza el Poder Ejecutivo y los legisladores de la coalición, que vulnera la Constitución, por tanto, como denomina Sant'Ana Pedra se trata de una mutación inconstitucional, o como denomina Risso Ferrand (2017) mutación “en sentido estricto”, porque dicha interpretación es una mutación constitucional derogatoria de la Constitución.

VIII.5) El artículo 256 de la Constitución señala que las leyes pueden ser declaradas inconstitucionales en razón de forma o de contenido, que la doctrina también llama razón "de forma” y “de materia” (Gomes Santoro, 2018).

La inconstitucionalidad es "de forma" cuando al elaborarse la ley se ha vulnerado alguna exigencia de procedimiento (Korzeniak, 2008).

El profesor Sánchez Carnelli (2005) citando Paul Duez señala refiriéndose a la inconstitucionalidad desde el punto de vista formal que "la ley que no reune sus elementos esenciales es un acto jurídico inexistente, que no ha nacido vivo".

Todo lo expuesto en los capítulos anteriores, nos conduce a concluir que existe inconstitucionalidad en razón “de forma", en el procedimiento que se aplicó para la aprobación de la ley $\mathrm{N}^{\circ} 19.889$.

Se vulnera implícitamente el límite que impone al Poder Ejecutivo el artículo 168 numeral $7^{\circ}$ literal a) de la Constitución: no presentar dos proyectos de ley con declaratoria de urgente consideración en forma simultánea.

Es así porque se presentó un proyecto de ley con declaratoria de urgente consideración de 501 artículos, aprobado con 476, que contiene los más diversos temas, que perfectamente podrían ser una treintena de leyes, por su contenido y extensión. 
VIII.6) Se vulnera el principio de separación de poderes.

El volumen de temas y artículos que contenía el proyecto de ley de urgente consideración, no permitió su estudio profundo por parte de los legisladores, lo que tuvo como consecuencia, por los plazos acotados con los que cuenta cada cámara para su aprobación -45 días la Cámara de Senadores, 30 días la Cámara de Representantes y 15 días en la Cámara de Senadores cuando en la Cámara de Diputados se modificaron algunos artículos del proyecto de ley-, que se sancionara sin un estudio serio de los temas.

En definitiva de lo descrito surge que se configuraron dos avasallamientos, del Poder Ejecutivo al Poder Legislativo y la mayoría del Parlamento a la minoría del mismo.

VIII.7) Uno de los principios que son importantes en el control de constitucional y que tiene relación con el principio de separación o división de poderes, es el de equilibrio en la relación de los poderes (Vázquez, 2018).

Esto significa que el órgano que controla la constitucionalidad, en este caso la Suprema Corte de Justicia, no abuse o se exceda en sus potestades, declarando la inconstitucionalidad de la ley sin una fundamentación sólida.

Y esto es así porque otro de los principios del control de constitucionalidad es de presunción de constitucionalidad de la ley (Vázquez, 2018).

En este caso, por los argumentos señalados, la Suprema Corte de Justicia, como órgano de control de la constitucionalidad de las leyes, tiene argumentos sólidos para declarar la inconstitucionalidad en razón de forma, de la ley $\mathrm{N}^{\circ} 19.889$.

VIII.8) Es importante en este tema, que las normas aprobadas por el Poder Constituyente sean respetadas por los Poderes constituidos.

Una de las innovaciones de la división de poderes es la relación que debe existir entre el Poder constituyente y las normas expedidas por los Poderes constituidos -Poder Ejecutivo y Poder Legislativo-, debiendo no contradecir éstos últimos la ratio legis de las normas constitucionales que aprobó el Poder Constituyente.

La profesora Lucas Garín (2009), señala como una nueva manifestación del principio de separación de poderes la división entre el Poder Constituyente y los Poderes constituidos. 
El Poder Ejecutivo y los legisladores de la coalición de gobierno, justamente lo que han hecho, es desconocer la voluntad del Poder Constituyente realizando una interpretación inconstitucional del término "urgencia” y presentando un proyecto de ley con un contenido y volumen que no está pensado para un proyecto de ley con declaratoria de urgente consideración.

Por ello es importante el control de constitucionalidad, por parte de la Suprema Corte de Justicia

En definitiva, por lo manifestado, la Suprema Corte de Justicia, si se lo solicitaren, debería declarar inconstitucional por razones de forma, la ley $\mathrm{N}^{\circ} 19.889$.

\section{CONCLUSIONES}

IX.1) En el proyecto de ley con el rótulo de urgente consideración, que entró en vigencia con el $\mathrm{N}^{\circ} 19.889$, el fin querido por el Poder Ejecutivo contradice el fin debido por la Constitución, por lo que se configuró desviación de poder.

IX.2) El Poder Ejecutivo al enviar un proyecto de ley con el rótulo de urgente consideración con 501 artículos y conteniendo más de treinta temas diferentes, denominado "ley ómnibus" - "omnibus bills"-, no permitió un estudio y discusión profunda de los temas por parte del Poder Legislativo.

IX.3) La interpretación del Poder Ejecutivo y de los legisladores de la coalición de gobierno del vocablo "urgencia" es erróneo, por tanto, se configuró una mutación constitucional.

IX.4) La ley $\mathrm{N}^{\circ} 19.889$ es inconstitucional en razón de forma por los siguientes fundamentos:

IX.4.1) El concepto de "urgencia" del artículo 168 numeral $7^{\circ}$ de la Constitución es de determinación objetiva, no subjetiva como lo interpreta el Poder Ejecutivo y los legisladores de la coalición de gobierno;

IX.4.2) La ley $\mathrm{N}^{\circ} 19.889$ vulnera el artículo 168 numeral $7^{\circ}$ literal a) de la Constitución, que señala que no se puede presentar más de un proyecto de ley con el rótulo de urgente consideración simultáneamente;

IX.4.3) La ley $\mathrm{N}^{\circ} 19.889$, vulnera los artículos 72 y 82 inciso $1^{\circ}$ de la Constitución, que consagran el principio de separación o división de poderes, por el avasallamiento del Poder Legislativo y principalmente la minoría del Parlamento. 
IX.5) Corresponde que la Suprema Corte de Justicia, como órgano garante de la Constitución, declare en la oportunidad que se lo soliciten, la inconstitucionalidad en razón de forma de la ley $\mathrm{N}^{\circ} 19.889$.

\section{BIBLIOGRAFÍA CONSULTADA}

AGUIRRE RAMÍREZ, Gonzalo (1985). "La Competencia del Poder Ejecutivo en la Constitución Nacional de 1967" en Temas de Derecho Constitucional 1. pp. 39-86. Montevideo, F.C.U.

AGUIRRE RAMÍREZ, Gonzalo (2008). "La proposición de las leyes" en Durán Martínez, Augusto (coord.) Estudios jurídicos en homenaje al profesor Daniel Hugo Martins. pp.33-56. Montevideo, F.C.U.

ARAGÓN, Manuel (1995). Constitución y control del poder. Buenos Aires. Ediciones Ciudad Argentina.

AVALOS, Eduardo (2012). "Los Decretos de Necesidad y Urgencia en Argentina: desde 1853 hasta nuestros días" en Revista de la Facultad de Derecho. Vol. 3 Núm. 1: Nueva serie II. pp. 147-157. Córdoba, Universidad Nacional de Córdoba. Recuperado el 28.11.2020 de: https://revistas.unc.edu.ar/index. $\mathrm{php} /$ refade/article/view/5972/6870

BARBAGElATA, Aníbal Luis (1985). "La Competencia del Consejo de Ministros en la Constitución Uruguaya de 1967" en Temas de Derecho Constitucional 1. pp. 5-18. Montevideo, F.C.U.

BOTTINELLI, Oscar (2020). Programa "Desayunos Informales" de canal Teledoce, de fecha 28 de enero de 2012. Recuperado el 20.10.2020 de: https://www.youtube.com/watch?v=Mw_ftLvPzMY

CAGNONI, José Aníbal (2006). El Derecho Constitucional Uruguayo. Montevideo, Segunda edición actualizada y ampliada.

CAGNONI, José Aníbal (2008). Separación, División, como Equilibrio de Poderes (Equilibrio entre ellos, equilibrio en ellos)" en Revista de Derecho Público. No. 33. pp. 7-13. Montevideo, F.C.U.

CAJARVILLE, Juan Pablo (2020). Semanario Búsqueda de fecha 27 de febrero de 2020. p. 42.

CASSINELLI MUÑOZ, Horacio (2009). Derecho Público. Montevideo, F.C.U, Tercera Edición.

CORREA FREITAS (2007). Derecho Constitucional Contemporaneo. Tomo I. Montevideo, F.C.U. Tercera Edición Actualizada.

CHASQUETTI, Daniel (2020). Diario La Diaria de fecha 24 de enero de 2020. Recuperado el 28.09.2020 de: https://ladiaria.com.uy/articulo/2020/1/los-proyectos-de-ley-de-urgente-consideracion-en-uruguay/

DE ARMAS, Gustavo y GARCÉ, Adolfo (1999). "Esa pasión uruguaya por la "Constituciones mixtas"” en Revista de Derecho Público No. 16. pp. 25-48. Montevideo, F.C.U. 
DELPIAZZO, Carlos E. (2011). Derecho Administrativo General. Volumen 1. Montevideo, Editorial Amalio M. Fernández.

DWORKIN, Ronald (2008). El imperio de la justicia. Barcelona, Editorial GEDISA, Tercera Reimpresión.

FERRAJOLI, Luigi (2016). Los derechos y sus garantías- Conversación con Mauro Barberis. Madrid, Editorial Trotta.

FLEITAS DE LEÓN, Luis (2019). “Una alerta Loewensteniana sobre el uso de las herramientas constitucionales de poder: aclaraciones sobre las leyes con declaratoria de urgente consideración" en Revista de Derecho Público, Año 28, N 55, pp. 69-76. Montevideo, F.C.U.

FLORES-DAPKEVICIUS, Rubén (2010). "Teoría general del control en Uruguay" en Cuestiones Constitucionales- Revista Mexicana de Derecho Constitucional. No. 22, enero-junio 2010. pp. 133155. México, Instituto de Investigaciones Jurídicas de la UNAM. Recuperado el 28.11.2020 de: file://C:/Users/Pablo/Downloads/5908-7869-1-PB\%20(1).pdf

GAMARRA, Diego (2014). “Interpretación de enunciados constitucionales y mutaciones en sentido débil en el ordenamiento jurídico uruguayo” en La Justicia Uruguaya. Tomo 149, Año 2014. pp. 57-66. Montevideo, Editorial La Ley Uruguay.

GARCÉ, Adolfo (2020). Diario El Observador de fecha 25 de abril de 2020. Recuperado el 20.10.2020 de: $\quad$ https://www.elobservador.com.uy/nota/-y-si-eliminamos-el-mecanismo-de-la-urgenteconsideracion--202042419570

GARCÍA ROCA, Francisco Javier (2000). "Del Principio de la División de Poderes" en Revista de Estudios Políticos (Nueva Época). Núm. 108. pp. 41-75. España. Centro de Estudios Políticos y Constitucionales. Recuperado el 28.11.2020 de: file://C:/Users/Pablo/Downloads/Dialnet-DelPrinc ipioDeLaDivisionDePoderes1-27611\%20(5).pdf

GARCÍA ROCA, Javier (2017). “Control parlamentario y convergencia entre presidencialismo y parlamentarismo" en Cuestiones Constitucionales- Revista Mexicana de Derecho Constitucional. No. 37, julio-diciembre 2017. pp. 3-49. México, Instituto de Investigaciones Jurídicas de la UNAM. Recuperado el 28.11.2020 de: file://C:/Users/Pablo/Downloads/11452-14404-1-PB\%20(1).pdf

GOMES SANTORO, Fernando (2018). “Objeto del proceso de inconstitucionalidad de la ley- Actos pasibles de ser declarados inconstitucionales” en VEIRAS, Jorge (coord.) Procesos Constitucionales. pp. 403422. Montevideo, F.C.U.

GROS ESPIELL, Héctor (1956). Las constituciones del Uruguay. Madrid, Ediciones Cultura Hispánica.

GROS ESPIELL, Héctor y ARTEAGA, Juan José (1991). Esquema de la evolución constitucional del Uruguay. Montevideo. F.C.U. Segunda Edición.

GUTIÉRREZ, Fulvio (2012). Manual Jurídico sobre los Gobiernos Departamentales. Montevideo, F.C.U. 
HÄBERLE, Peter (2016). El Estado Constitucional. México, Universidad Nacional Autónoma de México, Segunda Edición.

HERRERAVÁSQUEZ, Ricardo (1996). "Las medidas extraordinarias y los decretos de urgencia en el modelo constitucional peruano" en Revista Derecho PUCP, $\mathrm{N}^{\circ}$ 50. pp. 235-255. Lima, Pontificia Universidad Católica de Perú. Recuperado el 28.11.2020 de: http://www.derecho.uba.ar/publicaciones/pensar-enderecho/revistas/1/separacion-de-poderes-y-facultades-legislativas-del-presidente.pdf

JIMÉNEZ DE ARÉCHAGA, Justino (2016). Teoría del Gobierno. Montevideo, F.C.U., Segunda Edición.

KORZENIAK, José (2008). Primer Curso de Derecho Público -Derecho Constitucional. Montevideo, F.C.U, Cuarta Edición.

KORZENIAK, José (2020). Diario La República de fecha 7 de mayo de 2020. Recuperado el 20.10.2020 de: https://www.republica.com.uy/korzeniak-no-solo-es-inconstitucional-sino-un-verdadero-exabruptojuridico-id764559/

LANDA ARROYO, César (2003). "Los decretos de urgencia en el Perú" en Revista Pensamiento Constitucional, Año IX, Núm. 9. pp. 131-148. Recuperado el 25.11.2020 de: file:///C:/Users/Pablo/ Downloads/3320-12549-1-PB\%20(1).pdf

LOEWENSTEIN, Kart (1986). Teoría de la Constitución. Barcelona, Editorial Ariel, Cuarta Reimpresión.

LUCAS GARÍN, Andrea (2009). "Nuevas dimensiones del Principio de división de poderes en un mundo globalizado" en Estudios Constitucionales, Año 7, № 2. pp. 241-253. Centro de Estudios Constitucionales de Chile, Universidad de Talca. Recuperado el 20.9.2020 de: https://scielo.conicyt. cl/pdf/estconst/v7n2/art09.pdf

MORA-DONATTO, Cecilia (2010). "Oposición y control parlamentario en México" en Cuestiones Constitucionales- Revista Mexicana de Derecho Constitucional. No. 23, julio-diciembre 2010. pp. 121-151. México, Instituto de Investigaciones Jurídicas de la UNAM. Recuperado el 20.11.2020 de: file://C:/Users/Pablo/Downloads/5933-7890-1-PB\%20(1).pdf

MOREIRA, Constanza (1998). Reforma Constitucional y Estructura Política. pp. 119-135. Montevideo, Centro de Estudios Estratégicos 1815- Ediciones de la Banda Oriental.

ONAINDIA, José Miguel (2012). "Separación de poderes y facultades legislativas del presidente" en Revista Pensar en Derecho, $\mathrm{N}^{\circ}$ 1. pp. 43-58. Buenos Aires, Facultad de Derecho, Universidad de Buenos Aires. Recuperado el 20.11.2020 de:http://www.derecho.uba.ar/publicaciones/pensar-en derecho/ revistas/1/separacion-de-poderes-y-facultades-legislativas-del-presidente.pdf

PLANAS SILVA, Pedro (1993). "Decreto de urgencia y "medidas extraordinarias": Notas para una tipificación" en IUS ET VERITAS, Año IV (7). pp. 133-158. Recuperado el 20.10.2020 de: http:// revistas.pucp.edu.pe/index.php/iusetveritas/article/view/15404/15856

RISSO FERRAND, Martín (2010). ¿Qué es la Constitución? Montevideo, Universidad Católica de Uruguay. 
RISSO FERRAND, Martín (2017, 1). “Mutación e interpretación evolutiva de la Constitución - Dos casos uruguayos" en Estudios Constitucionales, Año 15, $\mathrm{N}^{\circ}$ 1, pp. 217-254. Centro de Estudios Constitucionales de Chile Universidad de Talca.

RISSO FERRAND, Martín $(2017,2)$. Guía para la resolución de de los casos de derecho Constitucional y Derechos Humanos. Montevideo, F.C.U.

RODRÍGUEZ ALMADA, Pablo (2020). Diario La Diaria de fecha 22 de mayo de 2020. Recuperado el 23.5.2020 de: https://adiaria.com.uy/articulo/2020/5/la-inconstitucionalidad-de-la-luc-en-materiade-adolescentes-infractores/

ROLLNERT LIERN, Göran (2014). “La mutación constitucional, entre la interpretación y la jurisdicción constitucional” en Revista Española de Derecho Constitucional. pp. 125-155. ISSN: 0211-5743, núm. 101, mayo-agosto (2014).

ROTONDO TORNARÍA, Felipe (2009). Manual de Derecho Administrativo. Montevideo, Ediciones del Foro. Sétima edición ampliada ya actualizada a junio de 2009.

RUIZ, José Fabián (2013). “¿Por qué prevalece el Estado de Derecho? Una aproximación comparada a las explicaciones centradas en la cultura de la legalidad" en Boletín Mexicano de Derecho Comparado, Nueva Serie, Año XLVI, Núm. 136, enero-abril 2013. pp. 239-285.

SÁNCHEZ CARNELLI, Lorenzo (2005). Declaración de Inconstitucionalidad de Actos Jurídicos. Montevideo, F.C.U.

SANT'ANA PEDRA, Adriano (2012). "La elasticidad del texto de la Constitución como límite para las mutaciones constitucionales" en Estudio Avanzados 17 (Jun. 2012). pp. 39-61. Recuperado el 25.9.2020 de: file://C:/Users/Pablo/Downloads/519-Texto\%20del\%20 art\%C3\%ADculo-1103-1-10-20120207\%20(3).pdf.

SAYAGUES LASO, Enrique (1987). Tratado de Derecho Administrativo. Tomo I. Puesta al día 1987 por el Dr. Daniel H. Martins. Montevideo, F.C.U, Quinta Edición.

YLARRI, Juan Santiago (2015). "La división de poderes en la emergencia económica en Argentina” en Cuestiones Constitucionales- Revista Mexicana de Derecho Constitucional. No. 32, enero-junio 2015. pp. 235-262. México, Instituto de Investigaciones Jurídicas de la UNAM. Recuperado el 20.11.2020 de Disponible en file://C:/Users/Pablo/Downloads/6089-8046-1-PB\%20(1).pdf

VÁZQUEZ, Cristina (2018). "Vías para promover la declaración de inconstitucionalidad de actos legislativos" en VEIRAS, Jorge (coord.) Procesos Constitucionales. pp. 443-471. Montevideo, F.C.U.

Fecha de recepción: 30 noviembre 2020 Fecha de aceptación: 6 marzo 2021 